\title{
The Application of Triple Aim framework in the context of Primary Healthcare: a systematic literature review
}

\begin{abstract}
Around the world, the Triple Aim framework is an increasingly popular tool for designing and assessing quality improvements in the healthcare sector. We systematically reviewed the empirical evidence on the application of the Triple Aim framework within primary healthcare settings since its inception almost a decade ago. Results showed that primary healthcare providers varied in their interpretation of the Triple Aim framework and generally struggled with a lack of guidance and an absence of composite sets of measures for performance assessment. Greater clarity around application of the Triple Aim framework in primary healthcare is needed, especially around the selection and implementation of purposeful measures from locally available data. This review highlights areas for improvement and makes recommendations intended to guide future Triple Aim applications in the context of primary healthcare.
\end{abstract}

Keywords: health policy; health system reforms; healthcare innovation; healthcare quality; redesigning healthcare organisations; Triple Aim

\section{Introduction}

Modern healthcare organisations are increasingly looking for creative ways to redesign complex and dated systems in order to embrace effective, efficient and sustainable healthcare delivery (Agrawal \& Conway, 2014; Bergevin et al., 2016; Glazman, 2017) further driven by a pressing need to balance rising costs of medical care with public expectations for delivery of high-quality care. In 2008, the Institute for Healthcare Improvement (IHI) introduced the Triple 
Aim framework with the primary goal of improving the value and quality of healthcare across three dimensions; the health of population, patient experience of care and per capita costs (Berwick, Nolan \& Whittington, 2008). The original intent was to provide a consolidated framework in order to guide systematic improvement initiatives associated with high quality healthcare services. Berwick and colleagues (2008) stressed that a strategic change, focused on all three dimensions simultaneously, at a system level, was needed in order to deliver desired outcomes. The authors believed that gains achieved in one dimension should not be at the expense of another and argued that a balanced and concurrent pursuit of all Triple Aim dimensions ensured equity and high-quality care delivery (Berwick, Nolan \& Whittington, 2008, p.760).

The value of the Triple Aim was recognised and adopted as the means of addressing deficits in the healthcare delivery system in the USA (Calman, Golub \& Shuman, 2012) following an introduction of the Affordable Care Act (labelled 'Obamacare') in 2010, and Triple Aim's subsequent adoption as the National Strategy for Quality Improvements in Healthcare (Tanenbaum 2016; US Department of Health \& Human Services, 2017). Various other developed nations have embraced the principles of the Triple Aim and sought to apply them in healthcare redesign (Hendrikx et al., 2016).

Since its inception almost a decade ago, the definition of the Triple Aim has remained consistent (Mery, Majumder, Brown, \& Dobrow, 2017), described by Berwick and colleagues (2008) as simultaneous pursuit of initiatives aimed at "improving the experience of care; improving the health of population; and reducing per capita costs" (Berwick et al., 2008, p.760). Yet, while the definition has remained consistent, there have been significant recent changes to the way in which it has been implemented and operationalized. In particular, the health of population increasingly focused on improved health outcomes and equity of care; experience of care concentrated on clinical quality rather than patient satisfaction; and per capita costs consisted of measures relating to waste reduction, affordability percentages, cost 
controls and higher efficiencies (Mery et al., 2017). Similarly, organisations appear to have consistently modified the Triple Aim framework in order to fit their own strategic objectives and local priorities or fulfil specific quality improvement aims (Whittington, Nolan, Lewis \& Torres, 2015). Further to this, some scholars identified that the original Triple Aim framework did not consider the experience of providers, advocating for inclusion of the critical role played by people tasked with delivery of care, and calling for the extension of the framework into a Quadruple Aim (Bodenheimer \& Sinsky, 2014; Sikka, Morath \& Leape, 2015).

Previous attempts to operationalise the Triple Aim framework have proven challenging, despite IHI publishing an authoritative guide on an informed approach to Triple Aim framework implementation and measures selection (Stiefel \& Nolan, 2012); and additional scholarly work on framework design and its operationalisation (Beasley, 2009; Verma \& Bhatia, 2016). Most commonly, healthcare organisations have struggled with identifying, in practical terms, what initiatives to measure within the Triple Aim framework, which essential processes and evaluation tools to implement and track over time, and how to scale the framework to different levels of healthcare systems (McNells, Genevro, \& Meyers, 2013; Ellison, 2012). Healthcare organisations need direction to successfully structure their practice environments in order to deliver quality patient care (Calman et al., 2012; Mery et al., 2017), and this is especially the case in the primary healthcare setting, where the value of Triple Aim framework has been recognised (Donahue et al, 2015; Kates et al, 2012). However, very little is known about the utility and the operation of the framework, the guiding systems and specific measures that organisations used in delivery of improvement initiatives. As such, current empirical evidence of Triple Aim application in the primary healthcare setting should be investigated. This context was considered appropriate, given the pivotal role of primary healthcare systems in delivering effective health outcomes has been widely acknowledged (Macinko, Starfield \& Shi, 2003; Starfield \& Macinko, 2005) 
This paper presents a systematic literature review on the operationalisation and application of the Triple Aim framework within the context of primary healthcare. The review sought to answer the following key question: What is the evidence of the application of the Triple Aim within the primary healthcare since its introduction in 2008? The aim was to investigate: 1) how was Triple Aim defined and operationalised in primary healthcare as primary improvement initiative and 2) how applicable is the Triple Aim within the primary healthcare system context. Addressing this aim allowed researchers to explore what is currently known about the Triple Aim framework as it has been reported within the primary healthcare context, draw conclusions on its usefulness, and consider what recommendations can be drawn for the future.

\section{Method}

The PRISMA statement guided this systematic literature review, by providing an outcome oriented methodological approach that is clear, transparent and reliable; a structured process that could be generalised and replicated in future studies (Liberati et al., 2009).

\section{Literature Review protocol}

The review protocol was developed by the Griffith university research team and key representatives from the Gold Coast Primary Health Network. Methods, aims and the scoping criteria were detailed in advance in order to capture the maximum number of published articles. Of particular interest were manuscripts that provided insights on the interpretation of the Triple Aim framework, it's concept designs, selection of parameters and formation of the essential criteria for each of the dimensions (e.g. how was the health of population defined and measured, what types of indicators were selected and why, and which types of data sets were collected). 
Types of studies: studies detailing whole of system delivery of the Triple Aim within the primary healthcare setting and articles discussing the conceptualisation and application of the Triple Aim framework were included. No date limit was applied with articles from any year of publication deemed eligible.

Type of interventions: Eligible papers had to describe the practical application of the Triple Aim in the primary healthcare context. This distinction was needed because numerous manuscripts made in-text reference to the overarching governance of the Triple Aim in their recommendations for system redesign, but provided little or no information on the actual framework or measures themselves.

The review process undertaken to narrow the search included early screening of the titles, abstracts and key words. In the instances where the use of the Triple Aim could not be determined from the abstract, a brief scan of the manuscript was undertaken to ascertain suitability. Most commonly this was the case with North American papers where the Triple Aim was adopted as part of a national health strategy and referred to often.

Studies published in English: Only work published in the English language was eligible for inclusion. While the review considered the Triple Aim framework application on an international level, there was no capacity to analyse texts in other languages.

\section{Search strategy}

Four electronic databases were searched: Medline (Ovid); Embase; Cinahl; and Healthcare Management Database (Proquest). A team of health sciences librarians were consulted in the search process, identification of suitable key words and the appropriate database selection. Final search terms were approved by the principal investigators. The search ran from 29 May 2017, with last update being completed on 12 June 2017. All identified articles were exported to EndNote for categorisation. To complement the search strategy, the reference lists in the identified papers were reviewed in order to identify other suitable articles. 
The initial search was performed in the Medline(Ovid) database using the term 'triple aim' and pairing it with phrases such as 'primary healthcare', 'measures', 'value based' or 'trade-offs' in order to identify potentially suitable studies (See Appendix A for full search items list). Such terms were considered broad, yet sufficient enough to allow for consideration of the Triple Aim Framework's application in the primary care by means of suitable measures. Moreover, all three dimensions of the Triple Aim, namely 'population health', 'experience of care' and 'per capita cost' were also used in the search process to identify articles discussing the frameworks components but not explicitly mentioning Triple Aim. The search was open to terms appearing anywhere in the abstract, title or full text. Embase, Cinahl and Healthcare Management Database (Proquest) databases were searched next in order to yield further papers. All identified papers were exported to EndNote for further consideration.

\section{Study selection}

In order to minimise individual bias, the principal study investigator oversaw the article selection process where article screening was performed by one researcher and nominated articles were subsequently reviewed by two other research members.

Following the title and abstract screening, 17 shortlisted full-text papers were retrieved and analysed. A brief statement was produced for each paper on the rationale for its inclusion or exclusion (see Appendix B). Of the 17 full text manuscripts that met the selection criteria for full assessment, 6 articles were deemed eligible for the qualitative synthesis based on the set criteria. The findings were categorised according to their relationship with the Triple Aim dimensions, using a balanced set of measures framework proposed by Stiefel and Nolan (2012) (see Appendix C). The sample size and scientific quality of the articles was not evaluated, because the primary interest of the review was to explore how the Triple Aim framework was applied, therefore all studies deemed as eligible were considered as equally important. 


\section{Results}

\section{General studies description}

The collective search of the four databases produced an initial total of 983 items (Figure 1). After duplicate records were removed, a total of 265 articles were examined in order to determine suitability and alignment to the primary study aims, with 17 full-text papers deemed eligible for inclusion, and a total of 6 papers fully analysed.

\section{Insert Figure1 here}

Of the 6 papers included in the analysis, 3 were published in 2015 or later, indicating that research evidence on the application of the Triple Aim by primary healthcare providers is recent. Evidence on the specific Triple Aim measures was found in the selected articles, with strong focus on the evaluation of the impact of the interventions at a practice level. An overview of the studies and the aggregate Triple Aim measures used are listed in Table 1.

\section{Insert Table 1 here}

A total of 75 individual healthcare providers were included across the 6 studies and the extent of Triple Aim application varied in size from initiatives at a single site level to a whole of province heath authority, but most commonly conducted at multiple sites at the district health service level. Considering the uptake of the Triple Aim at the global level, two papers reported on studies conducted in Canada (Table 1 , studies ${ }^{3,6}$ ), and remaining studies being from USA, New Zealand and Germany (Table 1, studies ${ }^{1,2,5}$ ) One study presented an international comparative analysis of Triple Aim across 20 providers in USA, Canada, England, New Zealand, Germany, Scotland and Spain (Table 1, study ${ }^{4}$ ). 
It is important to note that several countries have begun to use Triple Aim concepts in their healthcare redesign with findings published in languages other than English (De Ridder, Bourgeois, Van den Bogaert, \& Van der Brempt, 2017; Lasmarías et al., 2016; Meyer et al., 2017), and future consideration of such studies may be beneficial.

\section{Reasons for Triple Aim application}

All of the studies consistently documented conceptual frameworks based on the Triple Aim dimensions - population health, experience of care and cost per capita. After this point consistency and alignment across studies was limited with all papers reporting operationalisation of the Triple Aim differently, by aligning the dimensions based on their own strategic organisational principles or participating in larger improvement initiatives and collaborations. The USA study of 27 primary healthcare providers (Donahue et al., 2015) participated in a larger collaboration aimed at improving the care of health population, by using the Triple Aim framework, where the three dimensions, core measures, and specific indicators were determined in advance and aligned to the national reporting standards. Individual practices sought to achieve baseline reporting targets on at least one of the Triple Aim dimensions. On the other hand, the New Zealand study (Doolan-Noble et al., 2015) sought to develop a meaningful set of system level measures for the purpose of performance benchmarking and data comparison between health systems at the national and international scale. Different still, among the two Canadian studies, one study sought to assess the extent of alignment between the Triple Aim framework and existent performance indicators utilised by the primary healthcare providers (Ryan et al., 2016); whereas the other study involved purposeful selection by IHI as part of a larger initiative supporting the pursuit of the Triple Aim (Farmanova et al., 2017). In the international comparison study (Hendrikx et al.,2016), only 8 out of 20 initiatives had the primary goal of achieving the Triple Aim, instead desiring to accomplish better quality of care or achieve integration of services. Integration of care as a 
cost effective, higher quality business model was the primary objective of the German study (Hildebrandt et al., 2012).

\section{Selecting meaningful Triple Aim measures}

Measuring healthcare performance in a complex healthcare setting was challenging for primary healthcare providers in the studies, and organisations tended to use readily available indicators for practical reasons. Intervention measures utilised were diverse and varied in detail and complexity, spread across different sub-groups within the population of various compositions. Only Hendrikx et al. (2016) reported on the specific measures used by the providers when applying the Triple Aim Framework. In this study the evidence was based on information from various research institution websites and consultations with health population experts. The lack of academic guidance and direction to select meaningful Triple Aim measures is a major challenge to health care providers in planning and achievement of the improved quality of care by means of the Triple Aim framework.

\section{Measures for the Population Health}

The population health dimension of Triple Aim has been previously defined as the "health outcomes of a group of individuals, including the distribution of such outcomes within the group' (Kindig \& Stoddart, 2003). These groups are often geographically defined populations but can also be other groups such as ethnic groups, employees or disabled persons. Of the six studies included in the review, only two had clearly defined geographically bounded populations (Doolan-Noble et al., 2015; Hildebrandt et al., 2012), although in the German study the population was additionally defined by the membership with the specified healthcare insurer. The remainder of the studies had the population consisting of the government subsidised patients, private insurance patients, insured workers and non-insured general population (Donahue et al., 2015; Farmanova et al., 2017; Hendryxk et al., 2016). One paper 
reported major challenges in defining the target population and subsequently a very narrow sub population was used (Ryan et al., 2016).

Population measures most commonly used in the reviewed studies were categorised according to Stiefel and Nolan's (2012) Triple Aim framework balanced set of measures. Most frequently, population measures included indicators on disease specific outcomes and definitive chronic conditions. Specifically, studies selected indicators on health outcome measures such as mortality and life expectancy rates (Doolan-Noble et al., 2015; Farmanova et al., 2017; Hendrikx et al., 2012; Hildebrandt et al., 2012), preventive measures such as cancer screening and immunisation (Donahue et al., 2015; Doolan-Noble et al., 2015; Hildebrandt et al., 2012) and behavioural and physiological factor indicators such as smoking, alcohol consumption and obesity rates (Donahue et al., 2015; Farmanova et al., 2017; Hendrikx et al., 2012). All of the studies used some form of measures from the mandatory data reporting sets that were readily available at either regional or national level.

Surprisingly, there was limited attention in the reviewed literature to define the Triple Aim dimensions. Thus, not operationally defining the constructs resulted in studies reporting different outcomes, potentially because the definition of the health of population has not been clarified in the Triple Aim literature. From the theoretical perspective, primary healthcare providers need to invest in the careful consideration of the choice of measures as the means to operationally define each of the Triple Aim dimensions (Stiefel \& Nolan, 2012). Seeking alignment with the nationally available indicators is recommended, and inclusion of instruments that capture both population outcome measures as well as the activity based measures is highly desirable.

\section{Measures for the Experience of Care}


Since patient experience is often more than perception of the satisfaction alone, the Triple Aim scholars have proposed and subsequently used measures for both the quality of care and patient experiences in their research (Whittington et al., 2015). Studies included in this review predominantly used survey measures to evaluate experiences of care, such as collecting inhouse survey feedbacks on self-reported patient satisfaction levels (Donahue et al, 2015). Only two studies reported use of indicators for quality of care measures (Faramnova et al., 2017; Hendrikx et al., 2016), however, measures from both paper were not comparable with one another. Additionally, barriers to care were also measured, being assessed by the indicators capturing waiting times until the next available appointments (Donahue et al.,2015; Ryan et al., 2016). However, due to lack of operational definition on the experience of care, all studies predominantly focused on the quality of care rather than experience of care. This led to inconsistencies across studies in reported outcomes and varying indicators used to measure them. In one study, no evidence was found of any indicators used in assessing patient experience of care (Hildebrandt, 2012).

\section{Measures for the 'Per Capita Cost'}

Operationally, per capita cost was recognised by scholars as complicated to measure in the Triple Aim framework because of the difficulty in identifying targeted population size and lack of data detail needed for the calculations (Stiefel \& Nolan, 2012). Within the literature reviewed, costs measured were most often reported in terms of resource utilisation or cost avoidance, most frequently being number of emergency department presentations and hospital admission rates. Half of the studies used only utilisation measures to capture the cost dimension of the Triple Aim (Donahue et al., 2015; Doolan-Noble et al., 2015; Ryan et al., 2016) stating difficulties in obtaining the level of data needed for the calculation of per capita costs. Of the three studies that reported application of both per capita cost and utilisation rates measures, two reported limitations in data aggregation and data integrity, stating difficulties in accurate 
head-counting due to patients switching providers or seeking treatments in other practices (Donahue et al., 2015; Hendrikx et al., 2016).

Triple Aim guidelines identified that cost per capita is preferable over total expenditure measures (Stiefel \& Nolan, 2012). This is particularly considered useful because defined populations may change over time for a number of reasons. A disadvantage of using total expenditure is that it is difficult to determine if changes have occurred because of changes in costs or changes in inputs. For example, if increases in cost are associated with an increased pricing for services/resources or change in the size of the defined population. When choosing what cost measures primary healthcare providers additionally need to consider the availability of the actionable data at the sufficient detail, in order to accurately capture costs.

\section{Discussion}

The purpose of this literature review was to report on the evidence of the application of the Triple Aim framework and the extent to which it has been effectively adopted globally within the context of primary health care. The review found major differences across studies in the manner in which Triple Aim dimensions were defined and operationalised. These differences are likely to explain much of the variances in the findings presented in the literature, and therfore limit the comparability of these findings globally. While the Triple Aim framework is still evolving, firming up the operational definitions for each dimension would allow researchers and policy makers to determine suitable measurements that can then be used. Organisations seeking to implement the Triple Aim should produce succinct and clear definitions for each of the dimensions at an early stage of implementation. These definitions need to consider current best practice guidelines from the literature and apply them effectively to their operating context. For this reason, it is essential for organisation to invest in capacity building and ensure they have a comprehensive understanding of the framework before preceding to the implementation phase. 
Our results have shown that, almost a decade since its inception, the overall value of the Triple Aim framework in the context of primary healthcare is currently unclear. Because the pursuit of Triple Aim requires organisations to simultaneously pursue three different dimensions (Berwick et al., 2008) this requires substantial strategic planning and consideration of the potential trade-offs between meeting each of the dimensions in the local context. Our results do suggest that the majority of studies were unable to implement Triple Aim, which is a major weakness of the framework's effectiveness. There were several reasons why this was the case. First, challenges in defining the population or selecting a narrow sub population led to limited success in the desired outcomes of quality improvements (Farmanova et al., 2017; Hendrykx et al., 2016; Ryan et al., 2016). Second, without available data, it was impossible to pursue Triple Aim in primary healthcare, because the availability of relevant data was deemed crucial in informing strategies to further improve primary care (Donahue et al., 2015). Last, there was a positive correlation between the providers ability to implement Triple Aim framework and having dedicated data management personnel (Donahue et al., 2015; Farmanova et al., 2017).

In addition, in spite of a lack of relevant data, our findings suggest a key criteria for selecting indicators to measure and track performance and progress over time was data availability. Most of the studies chose to select individual indicators based on the primary data collection outputs readily available to them that carried minimal disruption to previously established processes. Implementing change in order to achieve Triple Aim was deemed essential but a challenging process, partly due to organisational, contextual and procedural factors such as the lack of understanding of how to best integrate a new framework within the existing organisational aims, strategic directions and visions, or how to extract needed data in order to effectively measure the impact of the Triple Aim framework on the provision of high quality care. This underlines our original point that before organizations choose to implement the framework, appropriate investment needs to be made into capacity building to ensure they 
have selected appropriate indicators, have access to the right data that tracks these indicators, as well as a comprehensive understanding of the framework before the implementation phase.

Across the three dimensions, assessing patient experience of care was perceived as the easiest data to collect, followed by the health of population measures. Per capita cost dimension predominantly concentrated on the cost avoidance (i.e. ED utilisation rates) rather than cost reduction. In most cases, a modified approach to data and dimensions alignment was needed in order to produce meaningful outcomes. Calls for major investment in infrastructure for primary data collection, analysis and reporting within primary care context were repeatedly made (Whittington et al., 2015; Ryan et al., 2016, Hendrikx et al., 2016) and a lack of these seen as detrimental for the ongoing future application of the framework.

How is Triple Aim defined and operationalised? The information and evidence acquired from the literature identified a major shortfall in the definitions of the main Triple Aim dimensions. For example, what is meant by the health of population, experience of care, or cost per capita? While a useful guideline for the balanced set of Triple Aim measures exists (Stiefel \& Nolan, 2015), only one study referred to it in the findings with limited success in the application of the framework (Ryan et al. 2016). This lack of clarity in definitions and measures was carried through the evolution of the framework and its varied application, because organisations interpreted and framed each of the dimensions differently. While these differences are attributed to different constraining factors such as policy, organisational resources or level of intervention, it can be argued that flexibility created by the lack of rigid definitions is both the strength as well as a weakness of the framework and the need for more explicit directive is needed.

When considering defining Population Health, an description used by Kindig and Stoddart (2003) should prove a strong starting point, namely being described as the health outcomes of a group of individuals, including the distribution of such outcomes within the group. Some 
questions to consider in this approach would be potential implications in adopting this definition. For example, will a population's health be made up of a geographical location or a sub group of individuals with particular comorbidities? Who would benefit from a particular approach and would there be a potential downside? Would any changes impact the rate of improvement and would they be significant enough to create an impact?

Consideration would also be needed on whether the selected approach could be easily replicated in similar conditions elsewhere. Considering potential variances in the design will assist in consistency across the measurements and potential ease of use in future interventions.

For the Experience of Care measures, only half of the identified studies utilised both quality of care and patient satisfaction measures. While the clinical quality of care is clearly defined by the Institute of Medicine as being safe, timely, patient centred, equitable, effective and accessible (Berwick, 2002), patient's perspective in receiving the treatment is often overlooked. Definition of patient experience as proposed by Wolf and colleagues (2014) which includes explaining usual practice and then measuring the expectations of patients in comparison to their actual experience of care afterwards is recommended as useful in the process. Wolf and others argued that patient experience reflects the occurrences and events that happen across the continuum of care where the patient experience becomes more than satisfaction of a single event, thus being strongly tied to a patient's expectations and whether they are positively realised (beyond clinical outcomes or health status).

Scholars have also called for the adaptation of the strategic approach to patient experience of care that moves beyond irregular episodic care to a holistic approach that incorporates both patient feedback and continuous patient engagement (Luxford \& Sutton, 2014). Studies going forward would benefit from broadening to a holistic approach that includes both of the measures as core elements of equal bearing. This would allow the experience of care measurement to include the quality of care outcomes and perceptions of how this is delivered, against the expectations. 
For Costs per Capita, our research found that studies reported varied measurements consisting of both directly observable costs, such as specific program per capita costs or indirect costs measured in terms of cost avoidance or cost control, such as the percent of the reduction in the hospital emergency presentations. However, no commonality was observed between them, and the difficulty in obtaining suitable data was most commonly stated as the hindering factor. Therefore, it is recommended that future studies consider measuring the direct costs as mandatory, and include measuring indirect costs where possible, in order to ensure that the costings presented remain transparent and easily replicated.

Also evident were the organisational environment challenges faced in the implementation of the Triple Aim framework (Whittington et al., 2015; Hildebrandt et al., 2016; Farmanova et al., 2017; Ryan et al., 2016). They included lack of leadership support, difficulty in creating partnerships, engagement and communication, limited time and resources, scoping of the improvement projects and lack of meaningful data. Recommendations for overcoming such barriers include starting small, and gradually expanding the scope of redesign, by seeking projects that naturally align with Triple Aim and are manageable within available resources. Also considered important is the need to include key stakeholders from the outset and invest in the team capacity building to ensure sustainability of new interventions is achieved.

Our review has also found that the dimensions of the Triple Aim framework are exclusive. That is, Ryan and colleagues study (2016) provideed evidence that performance in one area of the Triple Aim was not necessarily associated with performance in another area. Similarly, Donahue and colleagues (2015) stated that some USA case studies reported difficulty by individual practices in matching data reporting with the Triple Aim national benchmarks, due to essential data sets being housed in different databases, inevitably gravitating towards Triple Aim dimensions where ease of reporting was established, and neglecting the indicators deemed difficult to measure. 
It is difficult to ascertain why this is the case. Perhaps, given the limited resources, an increase in performance in one dimension may come at the expense of performance in another dimension. Or it is possible that certain sub-sections within the broader health services systems have priorities that are considered unique. Additionally, different measures may motivate managers to change evaluations to suit their own interests by heavily promoting high performing areas at the expense of areas needing improvement. No other study discusses weightings on specific measures, and therefore it can be concluded that healthcare organisations consider weightings on a case by case basis, usually aligning them to organisational purpose, objective and goals.

All of the studies in this review called for the development of a more consistent and robust set of measures to guide Triple Aim implementation. We recognise, however, that given the different goals and strategies of organisations, along with various ways that populations are defined in each context, it is unrealistic to expect such a complete consistent set of measures be implemented across different locations, populations and/or organisations. It is our hope however, that by improving the operational definitions of each of the three dimensions and providing stronger guidance around the measurement of each, that some consistency can be achieved which will allow for global comparisons and assist policy makers to use the framework more productively in the future.

\section{Conclusions}

The Triple Aim framework, while still under development, requires further consideration for its utility to be realised globally within the context of primary healthcare. This uniformity is especially necessary in the context of primary healthcare delivery where the organisations that are pursuing quality improvement interventions require readily available and widely applicable measures in order to evaluate population health, experience of care and per capita costs. 
Having clear operational definitions of these constructs going forward will reduce the weaknesses that exist in the literature to date and increase the quality of comparisons across projects. This is particularly important for those policy makers who are considering adopting the framework in order to ensure they have reliable benchmarks to measure their outcomes. Thus, with stronger and more consistent measurement tools and definitions, the literature underpinning the Triple Aim framework will continue to be of utility to policy makers globally. 


\section{References}

Agrawal, S. \& Conway, P. (2014, September). Aligning emergency care with the triple aim: Opportunities and future directions after healthcare reform. In Healthcare (Vol. 2, No. 3, pp. 184-189). Elsevier.

Beasley, C. (2009). The triple aim. Optimizing Health, Care and Cost.Healthcare Executive, 24(1), 64-66.

Bergevin, Y., Habib, B., Elicksen-Jensen, K., Samis, S., Rochon, J., Denis, J. L., \& Roy, D. (2016). Transforming Regions into High-Performing Health Systems Toward the Triple Aim of Better Health, Better Care and Better Value for Canadians. Healthcare Papers, 16(1), 34.

Berwick, D. M. (2002). A user's manual for the IOM's 'Quality Chasm'report. Health affairs, 21(3), 80-90

Berwick, D., Nolan, T., \& Whittington, J. (2008). The triple aim: care, health, and cost. Health affairs, 27(3), 759769.

Bodenheimer, T., \& Sinsky, C. (2014). From triple to quadruple aim: care of the patient requires care of the provider. The Annals of Family Medicine, 12(6), 573-576.

Bradbury, H., \& Lifvergren, S. (2016, November). Action research healthcare: Focus on patients, improve quality, drive down costs. In Healthcare Management Forum (Vol. 29, No. 6, pp. 269-274). Sage CA: Los Angeles, CA: SAGE Publications.

Callander, E. and Lindsay, D. (2016) .A performance framework for the North Queensland Primary Health Network, based upon the Quadruple Aims theory. Australian Institute of Tropical Health ad Medicine. Australian Institute of Tropical Health \& Medicine.

Calman, N. S., Golub, M., \& Shuman, S. (2012). Primary care and health reform. Mount Sinai Journal of Medicine: A Journal of Translational and Personalized Medicine, 79(5), 527-534.

De Ridder, R., Bourgeois, J., Van den Bogaert, S., \& Van der Brempt, I. (2017). Implementing integrated Care in Belgium: a nationwide mobilization. International Journal of Integrated Care, 17(5).

Donabedian, A. (1988). The quality of care: how can it be assessed? Jama, 260(12), 1743-1748

Donahue, K., Reid, A., Lefebvre, A., Stanek, M., \& Newton, W. (2015). Tackling the triple aim in primary care residencies: the I3 POP Collaborative. Family medicine, 47(2), 91-97.

Doolan-Noble, F., Lyndon, M., Hau, S., Hill, A., Gray, J., \& Gauld, R. (2015). How well does your healthcare system perform? Tracking progress towards the triple aim using system level measures. NZ Med Journal, 128(1415), 44-50.

Ellison, P. (2012). The challenge of advancing quality in Canadian primary healthcare. Healthcare Papers, 12(2), 24-8.

Farmanova, E., Kirvan, C., Verma, J., Mukerji, G., Akunov, N., Phillips, K., \& Samis, S. (2016). Triple Aim in Canada: developing capacity to lead to better health, care and cost. International Journal for Quality in Health Care, 28(6), 830-837

Glanzman, R. M. (2017). The Age of Value: Navigating the Transition From Volume to Value. Orthopaedic Nursing, 36(1), 5-9. 
Hendrikx, R. J., Drewes, H. W., Spreeuwenberg, M., Ruwaard, D., Struijs, J. N., \& Baan, C. A. (2016). Which Triple Aim related measures are being used to evaluate population management initiatives? An international comparative analysis. Health Policy, 120(5), 471-485.

Hildebrandt, H., Schulte, T., \& Stunder, B. (2012). Triple Aim in Kinzigtal, Germany: improving population health, integrating health care and reducing costs of care-lessons for the UK?. Journal of Integrated Care, 20(4), 205-222.

Kindig, D., \& Stoddart, G. (2003). What is population health? American journal of public health, 93(3), 380-383

Lasmarías, C., Delgado, S., Vila, L., González, S., Loncan, P., González, A., ... \& Gómez-Batiste, X. (2016). The Model of Advanced Care Planning in Catalonia (Spain). International Journal of Integrated Care, 16(6).

Liberati, A., Altman, D., Tetzlaff, J., Mulrow, C., Gotzsche, P., Ioannidis, J. P., Moher, D. (2009). 'The PRISMA statement for reporting systematic reviews and meta-analyses of studies that evaluate health care interventions: explanation and elaboration'. Annals of internal medicine, 151, 4, 65-94.

Lorgelly, P. K., Lawson, K. D., Fenwick, E. A., \& Briggs, A. H. (2010). Outcome measurement in economic evaluations of public health interventions: a role for the capability approach?. International journal of environmental research and public health, 7(5), 2274-2289

Luxford, K., \& Sutton, R. N. (2014). How does patient experience fit into the overall healthcare picture?. Patient Experience Journal, 1(1), 20-27.

Macinko, J., Starfield, B., \& Shi, L. (2003). The contribution of primary care systems to health outcomes within Organization for Economic Cooperation and Development (OECD) countries, 1970-1998. Health services research, 38(3), 831-865.

McNellis, R. J., Genevro, J. L., \& Meyers, D. S. (2013). Lessons learned from the study of primary care transformation. Annals of Family medicine,11(1), 2-5.

Mery, G., Majumder, S., Brown, A., \& Dobrow, M. J. (2017). What do we mean when we talk about the Triple Aim? A systematic review of evolving definitions and adaptations of the framework at the health system level. Health Policy.

Meyer, I., Hammerschmidt, R., Kubitschke, L., \& Müller, S. (2017). How to Make a Service Sustainable? An Active Learning Simulation Approach to Business Model Development for Integrated Care. In Handbook Integrated Care (pp. 277-294). Springer International Publishing.

Robertson-Preidler, J., Anstey, M., Biller-Andorno, N., \& Norrish, A. (2017). Approaches to appropriate care delivery from a policy perspective: A case study of Australia, England and Switzerland. Health Policy.

Ryan, B. L., Brown, J. B., Glazier, R. H., \& Hutchison, B. (2016). Examining Primary Healthcare Performance through a Triple Aim Lens. Healthcare Policy, 11(3), 19.

Sikka, R., Morath, J. M., \& Leape, L. (2015). The Quadruple Aim: care, health, cost and meaning in work. BMJ Quality \& Safety, 25(10), 608-610.

Starfield, B., Shi, L., \& Macinko, J. (2005). Contribution of primary care to health systems and health. The milbank quarterly, 83(3), 457-502. 
Stiefel, M., \& Nolan, K. (2012). A guide to measuring the triple aim: population health, experience of care, and per capita cost. IHI Innovation Series white paper. Cambridge, Massachusetts: Institute for Healthcare Improvement.

Struijs, J.., Drewes, H. W., Heijink, R., \& Baan, C. A. (2015). How to evaluate population management? Transforming the Care Continuum Alliance population health guide toward a broadly applicable analytical framework. Health Policy, 119(4), 522-529.

Tanenbaum, S. J. (2017). Can Payment Reform Be Social Reform? The Lure and Liabilities of the "Triple Aim". Journal of health politics, policy and law, 42(1), 53-71.

US Department of Health \& Human Services (2017). About the National Quality Strategy. Agency for Healthcare Research and Quality, Rockville, MD. Retrieved 05 June 2017, from http://www.ahrq.gov/workingforquality/about/index.html

Verma, A., \& Bhatia, S. (2016). A Policy Framework for Health Systems to Promote Triple Aim Innovation. Healthcare Papers, 15(3), 9-23.

West, C. P. (2016). Physician Well-Being: Expanding the Triple Aim.. Journal of General Internal Medicine,31(5), 458-459.

Whittington, J. W., Nolan, K., Lewis, N., \& Torres, T. (2015). Pursuing the triple aim: the first 7 years. The Milbank Quarterly, 93(2), 263-300.

Wolf, J., Niederhauser, V., Marshburn, D., \& LaVela, S. (2014). Defining patient experience: a critical decision for healthcare organizations. The Beryl Institute, Patient Experience Journal, 3-19. 


\section{Appendix A}

\section{Electronic database search strategy}

Example search - Medline (Ovid) Database - June 2017

\begin{tabular}{|c|c|c|}
\hline Search query terms & $\begin{array}{l}\text { Initial } \\
\text { results }\end{array}$ & $\begin{array}{l}\text { Exported to } \\
\text { EndNote }\end{array}$ \\
\hline 1. "triple aim" OR "quadruple aim" & 1873 & No \\
\hline 2."triple aim" OR "quadruple aim" AND measure* & 26 & Yes \\
\hline 3. "triple aim" OR "quadruple aim" AND dimensions & 165 & Yes \\
\hline 4."triple aim" OR "quadruple aim" AND trade-offs & 1 & Yes \\
\hline 5."triple aim" OR "quadruple aim" AND value OR "value-based" & 49 & Yes \\
\hline 6."triple aim" OR “quadruple aim “AND 'primary health care' OR 'primary healthcare' & 2 & Yes \\
\hline 7." population health" AND "experience of care" AND "per capita cost" & 79 & Yes \\
\hline 8."population health" AND "experience of care" & 19 & Yes \\
\hline 9."population health" AND "per capita cost" & 7 & Yes \\
\hline 10."experience of care" AND "per capita cost" & 5 & Yes \\
\hline 11. "population health" AND measure* & 17379 & No \\
\hline 12. "experience of care" AND measures* & 2643 & No \\
\hline 13. "per capita cost" AND measure* & 735 & No \\
\hline $\begin{array}{l}\text { 14.(population health) OR (experience of care) OR (per capita cost) AND (quality } \\
\text { improve*) }\end{array}$ & 285 & No \\
\hline $\begin{array}{l}\text { 15.(population health) OR (experience of care) OR (per capita cost) AND (quality } \\
\text { measure*) }\end{array}$ & 74 & Yes \\
\hline $\begin{array}{l}\text { 16. (population health) AND (experience of care) AND (per capita cost) AND } \\
\text { (evaluation framework) }\end{array}$ & 0 & $n / a$ \\
\hline
\end{tabular}

Total exported articles

Note: Limits applied to all searches: "Results in English". Phrases could appear anywhere including in the title, keywords, abstract or in-text so as to be all inclusive. Symbol * used for truncation. 
Appendix B

Triple Aim Systematic Review - paper inclusion justification

Citation Title \& purpose of the paper (as stated in abstract)
Meets TA/QA

inclusion criteria?
Include for review?

Justification/Comments
Aston, G. (2015)

What the EVOLUTION of one medical home can teach us all

Carlton Clinic, a medical home model facility pilot tested Triple aim with "focus on patient education, patient engagement and lifestyle changes to address chronic diseases. They began using technology to track patients.

\section{Bossaert,A.}

De Ridder, $\mathbf{R}$ (2017)

\section{Bradbury, $\mathrm{H}$.}

Lifvergren, $\mathrm{S}$.

(2016)

Calman, N.; Golub, M.

Shuman, S. (2012)

\section{Callander \& Lindsay,}

\section{Integrated care in Belgium: A co-creative process}

National Plan: "Integrated Care for a better health" was approved by all ministers of public health. This Plan is based on the principles of Triple Aim, and complementary principles of improving equity and job satisfaction for the care providers

\section{Action research healthcare: Focus on patients, improve quality, drive down costs}

Discuss action research in healthcare as a transformative approach ... in alignment to the "quadruple" aim. Insights from objective quantitative studies are balanced with personal and inter-subjective dialogue that aligns different parts of a system in a movement towards improvement. Evidence in Sweden.

Primary care and health reform

"This article provides an overview of models supported by the Affordable Care Act that address one or more goals of the "Triple Aim"

A performance framework for the North Queensland Primary Healthcare Network, based upon the Quadruple Aims Theory.

Yes

No- does not list any particular

framework or model in detail-just describes the benefits

No - no specific framework/model discussed

No - provides general overview of different primary health care models in USA, in line with recent reforms

No-research report intended to guide implementation only,

however not operationalized 


\begin{tabular}{|c|c|c|c|}
\hline Citation & Title \& purpose of the paper (as stated in abstract) & $\begin{array}{l}\text { Meets TA/QA } \\
\text { inclusion criteria? }\end{array}$ & $\begin{array}{l}\text { Include for review? } \\
\text { Justification/Comments }\end{array}$ \\
\hline & $\begin{array}{l}\text { Quadruple Aim evaluation framework design for an Australian Primary Heath Network. Proposed } \\
\text { measures include Australia specific outcome indicators based on readily available nationally collected } \\
\text { data sets }\end{array}$ & & \\
\hline $\begin{array}{l}\text { Donahue, K. et al } \\
(2015)\end{array}$ & $\begin{array}{l}\text { Tackling the triple aim in primary care residencies: the } 13 \text { POP Collaborative } \\
\text { We examine residency baseline triple aim measures, compare with national benchmarks, and identify } \\
\text { practice characteristics associated with data reporting }\end{array}$ & Yes & Yes \\
\hline $\begin{array}{l}\text { Doolan-Noble, F. } \\
\text { et al (2015) }\end{array}$ & $\begin{array}{l}\text { How well does your healthcare system perform? Tracking progress toward the triple aim using system } \\
\text { level measures } \\
\text { Tracking progress toward the triple aim using system level measures. The measurements adopted inform } \\
\text { quality improvement activity and compare performance nationally and internationally }\end{array}$ & Yes & Yes \\
\hline $\begin{array}{l}\text { Farmanova, E. et al } \\
(2016)\end{array}$ & $\begin{array}{l}\text { Triple Aim in Canada: developing capacity to lead to better health, care and cost } \\
\text { Canadian Foundation for Healthcare Improvement supported enrolment of nine Canadian teams to } \\
\text { participate in the Institute for Healthcare Improvement's TA Improvement Community. Structured } \\
\text { support for TA design, implementation, evaluation and sustainability was addressed in a collaborative } \\
\text { program. }\end{array}$ & Yes & Yes \\
\hline Hendrikx. R. et al (2016) & $\begin{array}{l}\text { Which Triple Aim related measures are being used to evaluate population management initiatives? An } \\
\text { international comparative analysis } \\
\text { This study explores how PM initiatives measure the Triple Aim in practice. }\end{array}$ & Yes & Yes \\
\hline $\begin{array}{l}\text { Hildebrandt, H. } \\
\text { Schulte, T. } \\
\text { Stunder, B. (2012) }\end{array}$ & $\begin{array}{l}\text { Triple Aim in Kinzigtal, Germany: Improving population health, integrating health care and reducing } \\
\text { costs of care -- lessons for the UK? } \\
\text { Emerging evidence about the qualitative and economic benefits of integrating care, based on an } \\
\text { innovative population-based approach across a small region of Germany }\end{array}$ & Yes & Yes \\
\hline Levine, J. et al 2011 & $\begin{array}{l}\text { Use of the Triple Aim to improve population health } \\
\text { CaroMont Health has embraced the Triple Aim initiative to implement its core vision and competencies } \\
\text { of delivering health care, promoting individual wellness, and creating vibrant communities. }\end{array}$ & Yes & $\begin{array}{l}\text { No- Not in primary healthcare } \\
\text { context. }\end{array}$ \\
\hline
\end{tabular}




\begin{tabular}{|c|c|c|c|}
\hline Citation & Title \& purpose of the paper (as stated in abstract) & $\begin{array}{l}\text { Meets TA/QA } \\
\text { inclusion criteria? }\end{array}$ & $\begin{array}{l}\text { Include for review? } \\
\text { Justification/Comments }\end{array}$ \\
\hline Polanco, N. et al (2015) & $\begin{array}{l}\text { Building integrated care systems: a case study of Bidasoa Integrated Health Organisation } \\
\text { This organisational case study used multiple data sources and methods in a pragmatic and reflexive } \\
\text { manner to build a picture of the organisational development over a 4-year period, based on Triple Aim } \\
\text { Framework }\end{array}$ & Yes & $\begin{array}{l}\text { No- a generalist overview of TA } \\
\text { stated with no specific framework }\end{array}$ \\
\hline $\begin{array}{l}\text { Robertson-Preidler, et } \\
\text { al. (2017) }\end{array}$ & $\begin{array}{l}\text { We conceptualized system appropriateness by identifying policies that aim to achieve the Triple Aim and } \\
\text { their consequent trade-offs for financing, clinical practice, and the individual patient". }\end{array}$ & Yes & $\begin{array}{l}\text { No- states appropriateness of } \\
\text { different approaches at the heath- } \\
\text { care system level. }\end{array}$ \\
\hline $\begin{array}{l}\text { Ryan, B. et al. } \\
\text { (2016) }\end{array}$ & $\begin{array}{l}\text { Examining Primary Healthcare Performance through a Triple Aim Lens } \\
\text { This study sought to apply a Triple Aim framework to the measurement and evaluation of primary } \\
\text { healthcare }(\mathrm{PHC}) \text { team performance }\end{array}$ & Yes & Yes \\
\hline $\begin{array}{l}\text { Sharma, A } \\
\text { Grumbach, K. } \\
\text { (2017) }\end{array}$ & $\begin{array}{l}\text { Engaging patients in primary care practice transformation: theory, evidence and practice } \\
\text { Much less is understood about engaging patients as partners in practice improvement at the primary } \\
\text { care clinic or practice level. }\end{array}$ & Yes & $\begin{array}{l}\text { No-alignment of one dimension of } \\
\text { TA presented, in the context of } \\
\text { primary care, however solely } \\
\text { focusing on patient engagement }\end{array}$ \\
\hline Shuker,K et al, (2015) & $\begin{array}{l}\text { The Health Quality and Safety Commission: making good health care better } \\
\text { The New Zealand Triple Aim has been defined as: improved quality, safety and experience of care; } \\
\text { improved health and equity for all populations; and best value for public health system resources. }\end{array}$ & Yes & $\begin{array}{l}\text { No-general article, No specific } \\
\text { framework }\end{array}$ \\
\hline $\begin{array}{l}\text { Whittington, J. W., } \\
\text { Nolan, K., Lewis, N. \& } \\
\text { Torres, T. (2015) }\end{array}$ & $\begin{array}{l}\text { Pursuing the triple aim: the first } 7 \text { years } \\
\text { Original coauthors of Triple Aim consider how the implementation of the Triple Aim progressed over the } \\
\text { first } 7 \text { years -with two detailed case studies presented on the Framework implementation }\end{array}$ & Yes & $\begin{array}{l}\text { No-article discusses major } \\
\text { principles and lessons learned }\end{array}$ \\
\hline
\end{tabular}


Triple Aim Framework - proposed balanced measures

\begin{tabular}{|c|c|}
\hline $\begin{array}{l}\text { Dlmenslon of the } \\
\text { IHI Trlple Alm }\end{array}$ & Outcome Measures \\
\hline \multirow[t]{3}{*}{ Population Health } & $\begin{array}{l}\text { Health Outcomes: } \\
\text { - Mortality: Years of potential life lost; life expectancy; standardized mortality } \\
\text { ratio } \\
\text { - Health and Functional Status: Single-question assessment (e.g., from CDC } \\
\text { HRQOL-4) or multi-domain assessment (e.g., VR-12, PROMIS Global-10) } \\
\text { - Healthy Life Expectancy (HLE): Combines life expectancy and health status } \\
\text { into a single measure, reflecting remaining years of life in good health }\end{array}$ \\
\hline & $\begin{array}{l}\text { Dlsease Burden: } \\
\text { Incidence (yearly rate of onset, average age of onset) and/or prevalence of } \\
\text { major chronic conditions }\end{array}$ \\
\hline & $\begin{array}{l}\text { Behavloral and Physlologlcal Factors: } \\
\text { - Behavioral factors include smoking, alcohol consumption, physical activity, } \\
\text { and diet } \\
\text { - Physiological factors include blood pressure, body mass index (BMI), } \\
\text { cholesterol, and blood glucose } \\
\text { (Possible measure: A composite health risk assessment [HRA] score) }\end{array}$ \\
\hline \multirow[t]{2}{*}{ Experlence of Care } & $\begin{array}{l}\text { Standard questions from patient surveys, for example: } \\
\text { - Global questions from Consumer Assessment of Healthcare Providers and } \\
\text { - Systems (CAHPS) or How's Your Health surveys } \\
\text { - Likelihood to recommend }\end{array}$ \\
\hline & $\begin{array}{l}\text { Set of measures based on key dimenslons (e.g., Institute of Medicine's } \\
\text { six aims for improvement: safe, effective, timely, efficient, equitable, and } \\
\text { patient-centered) }\end{array}$ \\
\hline \multirow[t]{2}{*}{ Per Caplta Cost } & Total cost per member of the population per month \\
\hline & Hospltal and emergency department (ED) utilization rate and/or cost \\
\hline
\end{tabular}

Source: (Stiefel \& Nolan, 2012). 
Tables \& Figures

Figure 1: Triple Aim -Scoping for systematic literature review
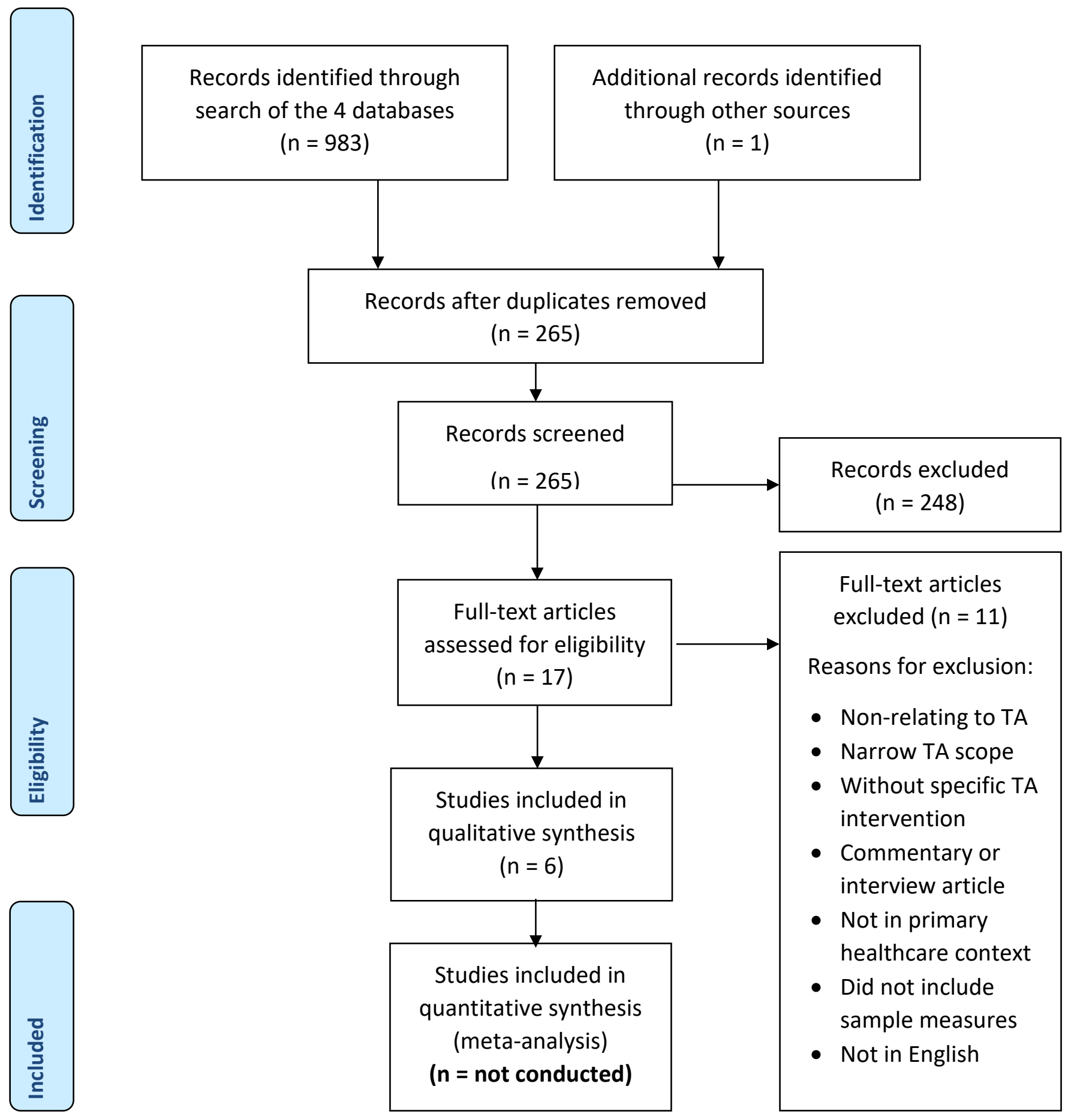
Table 1 Study measures summary, categorised according to the Triple Aim Framework

\begin{tabular}{|l|l|l|}
\hline No & Author & year \\
\hline 1 & Donahue et & 2015
\end{tabular}

al.

\section{Level of application}

27 single site primary

care providers

delivering family,

internal and pediatric

medicine in USA

\section{Experience of Care Measures}

Provider continuity of care;

variety of in-house patient

satisfaction surveys;

timely access measure to the next available appointment

\section{Population Health Measures}

Health outcome measures: preventative

colorectal cancer screening, nephropathy screening, mammography screening, flu shot, immunization rates in children

Disease burden measures: any two of chronic disease measures - diabetes, hypertension, cognitive heart failure, aspirin use, asthma, obesity, ADHD

\section{Cost Measures}

Utilisation rates: Hospitalisation rate per 10000; ED visit rate; readmission rate; subspecialty referral rate; high end radiology referral rate $(\mathrm{CT}, \mathrm{MRI}, \mathrm{PET}$ scans per 1000).

Behavior factors: smoking/cessation rates

\section{Doolan-} Noble, et al.

\section{1 district health board \\ Patient experience of care survey} providing hospital care, integrated care and primary healthcare services in New Zealand

Institute of medicine quality of care measures: hospital standardized mortality ratios, adverse events, patient health
Farman
et al.

2017

\section{Canadian sites delivering a mix of} primary and secondary healthcare - district health services, individual hospitals, service utilisation rates, access and waiting times, acute hospital readmission rates

\section{Surveys: likelihood of}

recommendation; global experience of care questions

Institute of medicine quality of care measures: best practice, rates of infection, access to primary
Health outcome measures: mortality rates, life expectancy at birth, hospital days during last 6 months of life

Disease burden measures: childhood immunization status, long term health condition risk assessment

Other: un-enrolled, waitlist for elective surgery, timely access to diagnostic services Health outcomes measures: mortality rates, years of potential life lost, life expectancy, standard mortality, crude death rate, infant mortality, neonatal mortality, self-reported health status, health related quality of life, health life expectancy rates
Utilisation rates: ED length of stay rates; total healthcare cost per capita; ambulatory services hospitalisation rates

Other: workforce retention rates Per capita cost measures: expenditure per capita, age adjusted spending per person, total monthly cost per member

Utilisation rates: hospitalisation rate, readmission rate, length of 
Disease burden: yearly rate of onset, average age of onset, prevalence of major condition, incidence and prevalence rates, $\%$ of population with condition, $\%$ of population with no chronic illness

Cost Measures

stay, number of beds per 1000 people, ED visits per 1000 people, ED cost per visit, ED share of hospital expenditure

Behavioral /physiological factors: smoking, alcohol, diet, physical activity, blood pressure, BMI, cholesterol, blood glucose

Other: social determinates-obesity rate, age, education, housing status, income level

Hendrikx et 2016 International al. comparative study

consisting of 20

population management initiatives by government led and private healthcare providers; delivering care to a mix of national, state and local populations. Studies done in USA, England, Canada, New Zealand, Germany, Scotland \& Spain.
Various patient satisfaction and reporting surveys, complaints about care rates

Institute of medicine quality of care - various measures most commonly on effective care, follow up care, preventive screening rates; patient safety measures on infection and complication rates, responsiveness, communication; timeliness, accessibility to medical acre, waiting times for inpatient care

\section{Health outcome measures: most commonly} included mortality rates, overall health status, life expectancy rates, quality of life, dependent patient prevalence rate $\%$ of population with multi-medication use

Disease burden: rates of disease prevalence, illness burden measures, comorbidities, care utilisation rates

Behavior and physiological factors: smoking, obesity, drink driving related deaths, vaccine uptake rate

Other: social inclusion rates, employed with disability rates
Per capita cost measures: average cost of care, volume of care expenditure, substitution rates, organisational cost of population management, financial performance

\section{Utilisation rates: ED} presentation rates, hospital readmission rates, , number of insurance claims, surplus \% of health commissioned spending, delivery of improvements and savings plans

Other: \% of staff turnover rates, $\%$ of patients switching insurance providers 


\begin{tabular}{|c|c|c|c|c|c|c|}
\hline No & Author & year & Level of application & Experience of Care Measures & Population Health Measures & Cost Measures \\
\hline 5 & $\begin{array}{l}\text { Hildebrandt } \\
\text { et al. }\end{array}$ & 2012 & $\begin{array}{l}1 \text { regional integrated } \\
\text { healthcare insurer in } \\
\text { Germany }\end{array}$ & $\begin{array}{l}\text { Experience of care surveys by } \\
\text { independent researchers looking } \\
\text { at the overall satisfaction with } \\
\text { quality of care }\end{array}$ & $\begin{array}{l}\text { Health outcomes measures: numerous } \\
\text { prevention and health promotion programs } \\
\text { including rate of fracture for patients with } \\
\text { osteoporosis; } \\
\text { Disease burden measures: rates of chronic } \\
\text { coronary heart disease, heart failure survival, } \\
\text { diabetes, affective disorders, dementia and } \\
\text { chronic back pain, rates of unspecified and } \\
\text { specified diagnosis, rate of recommended } \\
\text { prescription drugs. }\end{array}$ & $\begin{array}{l}\text { utilisation rates: Charlson score } \\
\text { (co-morbidity) assessment by } \\
\text { German risk structure } \\
\text { compensation, overall costs per } \\
\text { patient, contribution margins, } \\
\text { hospitalisation rates and hospital } \\
\text { cost rates per } 1000 \text { patients }\end{array}$ \\
\hline 6. & Ryan et al & 2016 & $\begin{array}{l}17 \text { single and multi- } \\
\text { site primary healthcare } \\
\text { providers in Canada }\end{array}$ & $\begin{array}{l}\text { Care experience rates for patient } \\
\text { centeredness, after-hours access, } \\
\text { timely access-next available } \\
\text { appointment. Sourced via survey }\end{array}$ & $\begin{array}{l}\text { Disease burden measures: cancer screening } \\
\text { rates, diabetes care rates }\end{array}$ & $\begin{array}{l}\text { Per capita cost measures: GP } \\
\text { visit per patient cost, ED visit } \\
\text { costs, hospitalisation costs } \\
\text { utilisation rates: number of ED } \\
\text { visits, low-urgency ED visits, } \\
\text { potentially avoidable } \\
\text { hospitalisations rates }\end{array}$ \\
\hline
\end{tabular}

